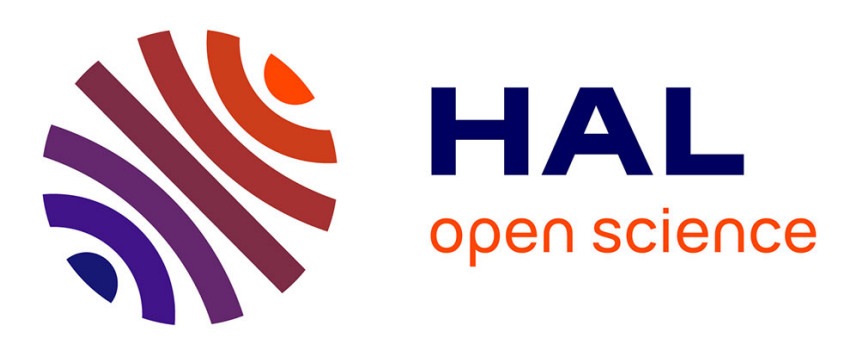

\title{
Investigation of Inductive and Radiating Energy Harvesting for an Implanted Biotelemetry Antenna
}

Quang-Trung Luu, Stavros Koulouridis, Antoine Diet, Yann Le Bihan, Lionel Pichon

\section{- To cite this version:}

Quang-Trung Luu, Stavros Koulouridis, Antoine Diet, Yann Le Bihan, Lionel Pichon. Investigation of Inductive and Radiating Energy Harvesting for an Implanted Biotelemetry Antenna. 11th European Conference on Antennas and Propagation (EUCAP), Mar 2017, Paris, France. 10.23919/eucap.2017.7928620 . hal-01633025

\section{HAL Id: hal-01633025 \\ https://hal.science/hal-01633025}

Submitted on 19 Aug 2020

HAL is a multi-disciplinary open access archive for the deposit and dissemination of scientific research documents, whether they are published or not. The documents may come from teaching and research institutions in France or abroad, or from public or private research centers.
L'archive ouverte pluridisciplinaire $\mathbf{H A L}$, est destinée au dépôt et à la diffusion de documents scientifiques de niveau recherche, publiés ou non, émanant des établissements d'enseignement et de recherche français ou étrangers, des laboratoires publics ou privés. 


\title{
Investigation of Inductive and Radiating Energy Harvesting for an Implanted Biotelemetry Antenna
}

\author{
Quang-Trung Luu ${ }^{2}$, Stavros Koulouridis ${ }^{1}$, Antoine $\operatorname{Diet}^{2}$, Yann Le Bihan ${ }^{2}$, Lionel Pichon ${ }^{2}$ \\ ${ }^{1}$ School of Electrical and Computer Engineering, University of Patras, Patras, Greece. E-mail: koulouridis@g.upatras.gr \\ ${ }^{2}$ Group of Electrical Engineering - Paris, UMR 8507 CNRS, CentraleSupelec, Université Paris-Sud, \\ Université Pierre et Marie Curie Gif-sur-Yvette, France. Email: lionel.pichon@geeps.centralesupelec.fr
}

\begin{abstract}
A coil is integrated inside an implanted antenna in order to support inductive charging. The implanted antenna has been designed for wireless data telemetry at $400 \mathrm{MHz}$ region and radiating wireless charging at $915 \mathrm{MHz}$. The antenna-coil system is embedded into a three-layer canonical model of human arm. In the inductive charging case an external transmitting coil is considered while in the radiating charging scenario a dipole is implemented. Several simulations are carried out for the antenna-coil system. While radiating charging seems to be more efficient, inductive charging can be used as a complimentary solution since they both can coexist.
\end{abstract}

Index Terms-Planar Inverted F-Antenna, coil configuration, SAR, efficiency.

\section{INTRODUCTION}

Electromagnetic (EM) energy has been proposed as alternative source for permanent implants or for utilizing battery-less implanted devices. For years the focus has been put on inductive power transfer through the use of coils but lately the so called Radio Frequency (RF) or Radiating approach has been considered. The later has been initiated by the need to design autonomous implants of very small sizes that support wireless signal transmission.

Indeed, miniaturized antennas operating in the $400 \mathrm{MHz}-$ $2500 \mathrm{MHz}$ have been proposed in several configurations for supporting wireless biotelemetry. For example in [1] a planar antenna operating in the $400 \mathrm{MHz}$ MedRadio Band has been proposed while in [2] a miniaturized planar dipole has been introduced for in-body communication at the same frequency and a wire dipole antenna has been developed in $950 \mathrm{MHz}$ region [3]. Other works focus on ISM $2.45 \mathrm{GHz}$ frequency band.

Inductive wireless transfer for implanted devices has been based on several coil configurations systems in very close distances in-between (in terms of wavelength). By proposing designs at $\mathrm{kHz}$ region or at frequencies of few $\mathrm{MHz}$, efficient designs have been obtained. Still the coil sizes have been kept relatively large. Lately, in order to minimize coil sizes, the sub-GHz area [4]-[5] has been proposed. The use of 1-2 mm diameter loops could lead to combined designs of inductive circuits with antennas that support wireless charging and medical telemetry. The idea is that very small loops would not affect the relative larger antennas while the larger loops (lower frequencies) could interact with antenna and affect its performance. Still, the use of inductive loops requires distances between external applicator and implanted receiver of 1-2 cm [4]-[5] and therefore placement of the external applicator directly on the body. Moreover, displacement of the external applicator or unwanted misalignment between external and internal system can greatly affect wireless transmission performance. In any case such problems have been addressed but not necessarily solved [6], [7].

Radiating (or RF) charging propose an alternative path. Use of antennas for wireless energy transmission could possibly achieve greater distances and robust designs combined with greater efficiencies. Work in this field is not extended. A triple band telemetry application with wireless energy transfer at $433 \mathrm{MHz}$ is investigated in [8] while in [9] and [10] harvesting is investigated at $2.45 \mathrm{GHz}$. In [11] a novel miniaturized rectenna for wireless telemetry and power transfer at MedRadio (402-405 MHz) and ISM (902.8-928 $\mathrm{MHz}$ ) bands, correspondingly, has been proposed.

In this work we are exploring the idea of integrating inductive wireless charging in the $15 \times 15 \times 1.25 \mathrm{~mm}^{3}$ antenna of [11]. We also draw some comparisons with the work in [11]. A first approach was discussed in [12]. The main restriction applied is the embedding of the proposed device in depths larger than $10 \mathrm{~mm}$ and the use of frequencies below $1 \mathrm{GHz}$. This is supported from multiple resources. For example in [13] it is analyzed how the use of lower frequency allows for higher power reception especially for depths larger than a cm. From [4]-[5] it is also indicated that the use of sub$\mathrm{GHz}$ region is the optimum for inductive coupling in realistic scenarios.

\section{GEOMETRY OF THE SYSTEM}

The geometry of the implemented antenna is given in Fig. 1 [11]. The patch is printed on a high-dielectric substrate (Rogers RO 3210, $\varepsilon_{\mathrm{r}}=10.2, \tan \delta=0.003$ ) of $0.625 \mathrm{~mm}$ thickness $(t)$ and is covered with an identical superstrate layer. The metallic patch surface (denoted with grey) and the ground plane have planar dimensions of $13.8 \mathrm{~mm} \times 15.8 \mathrm{~mm}$ and 14 $\mathrm{mm} \times 16 \mathrm{~mm}$, respectively. With reference to Fig. 1a, the slots $w_{1} \times l_{l}$ and $w_{2} \times l_{2}$ are open to tune the antenna at MedRadio band. The addition of $w_{3} \times l_{3}$ slot allows for additional antenna operation at $915 \mathrm{MHz}$ for the radiating charging operation. A shorting pin (point $\mathrm{S}$ ) increases the effective antenna size and further enhances antenna miniaturization (see [11] for further details).

In order to add inductive charging capabilities, the antenna is loaded with a coil tuned with a matching circuit. Coil 
diameter does not exceed 1-2 $\mathrm{mm}$. It should be noted that width $\mathrm{w}_{2}$ is initially $\mathrm{w}_{2}=1.2 \mathrm{~mm}$. However, because of the antenna capability for tuning the width can be increased and allow for up to $2 \mathrm{~mm}$ diameter coils. At one possible scenario the antenna carries out the medical telemetry communication while the coil is the main component of the wireless power harvester or alternatively harvesting at two different frequencies; i.e. the coil frequency and the far field (Radiating Charging) frequency (915 MHz, see [11]). In other words, the coil does not affect antenna operation at all.

The system is implanted into a canonical (cylindrical) three layered tissue arm model consisting of skin (thickness $2.5 \mathrm{~mm}$ ), muscle (thickness $25 \mathrm{~mm}$ ), and bone (see Fig. 2). The dielectric constants of the tissue model are evaluated at $402 \mathrm{MHz}$ and $915 \mathrm{MHz}$, respectively [14]-[16]. The antenna is placed at a depth $\mathrm{d}=10 \mathrm{~mm}$ beneath the skin-air interface. Depending on the scenario, an external antenna, at $1 \mathrm{~m}$ from the external surface for example, transfers radiating energy or an external coil configuration, at a few $\mathrm{mm}$ from the surface, transfers energy inductively. Electromagnetic analysis is carried out with CST Microwave Studio ${ }^{\mathrm{TM}} 2015$.

\section{INDUCTIVE ENERGY TRANSFER SYSTEM}

Due to the restrictions of internal coil diameter, the frequency region investigated is the sub-GHz region. Indeed in [4], [5] where similar internal coil sizes are investigated the optimum frequency seems to variate between $100 \mathrm{MHz}$ and $900 \mathrm{MHz}$. We set internal coil diameter to be $1 \mathrm{~mm}$. For the external coil the diameter implemented is set to $24 \mathrm{~mm}$. Internal coil has 7 turns while the external one has a single turn.

The system $\mathrm{Tx}-\mathrm{Rx}$ coils is analyzed using the equivalent circuit given in Fig. 3 (see also [4]) The induction between the Tx and the Rx coil is being represented by the 2-port matrix that is evaluated by defining feeding ports at the Tx and $\mathrm{Rx}$ coils. After Electromagnetic Analysis, Power Transfer Efficiency (PTE) is obtained via circuit analysis, as given in Eq. (1) [4]. PTE is actually the ratio of real power deposited at the load $\mathrm{Z}_{\mathrm{L} \text {,orig }}$ over the power inserted at the Tx coil. No mismatch losses between the feeding source $\mathrm{V}_{\mathrm{s}}$ and the coil system is taken into account.

$$
\begin{aligned}
P T E & \approx \frac{\left|Z_{21}\right|^{2}}{\left|\operatorname{Im}\left(Z_{11}\right) \operatorname{Im}\left(Z_{22}\right)\right|} \times \frac{\left|\operatorname{Im}\left(Z_{11}\right)\right|}{\operatorname{Re}\left(Z_{11}\right)} \\
& \times \frac{\left|\operatorname{Im}\left(Z_{22}\right)\right|}{\operatorname{Re}\left(Z_{22}\right)+\operatorname{Re}\left(Z_{L}\right)} \times \frac{\operatorname{Re}\left(Z_{L}\right)}{\operatorname{Re}\left(Z_{22}\right)+\operatorname{Re}\left(Z_{L}\right)} \\
& =\kappa^{2} Q_{T X} Q_{L} \eta_{R x} .
\end{aligned}
$$

For design purposes the transmission-reception inductive system was first tested without the antenna presence and with the receiving coil placed either in the air or inside the arm model. The distance between $\mathrm{Tx}$ and Rx coil was set equal to $12 \mathrm{~mm}$. The Rx coil was placed at $10 \mathrm{~mm}$ depth from the arm surface (i.e. the Tx coil was at $2 \mathrm{~mm}$ distance from the arm surface). As can be seen in Fig. 4 the tissue environment affects the optimum power efficiency significantly. With the receiving coil inside the arm model the maximum power efficiency is found to be $1.59 \%$ at $86.81 \mathrm{MHz}$.

Subsequently, the Rx coil is embedded inside the antenna as seen in Fig. 1 and Fig. 2. As seen in Fig. 5 the optimum frequency is not considerably affected and is now found to be 104.45 MHz. However, the Power Transfer Efficiency is considerably decreased falling to $0.48 \%$. As has been investigated (not shown here) the antenna ground plane affects considerably the PTE. Still by increasing the Rx coil diameter or altering the antenna backing (without affecting its performance can partially restore the worsened power efficiency.

\section{EVALUATING INDUCTIVE AGAINST RADIATING ENERGY HARVESTING AND DISCUSSION}

The wireless power link is evaluated between either the external antenna (here a dipole) or the Tx coil $24 \mathrm{~mm}$ in

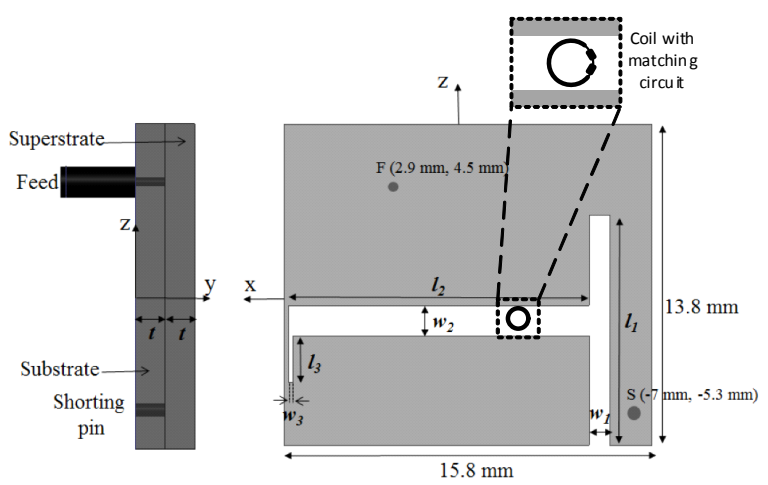

Fig. 1. Geometry of the proposed implantable PIFA operating at $402 \mathrm{MHz}$ and $915 \mathrm{MHz}$, respectively ([11]).

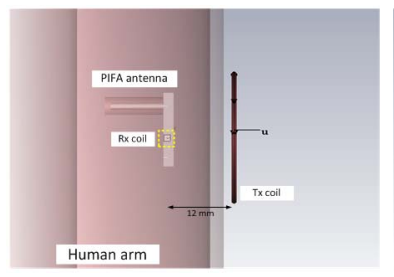

(a)

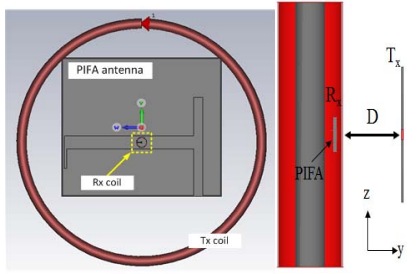

(b)

(c)
Fig. 2. Wireless power link simulation set-up (a), (b) inductive and (c), radiating. The antenna with the coils (Receiver-Rx) is implanted into the cylindrical arm model and either an external coil configuration (here circular coil) or an external antena (here a linear dipole) (Transmitter-Tx) transfer the energy to the Receiver - Rx.

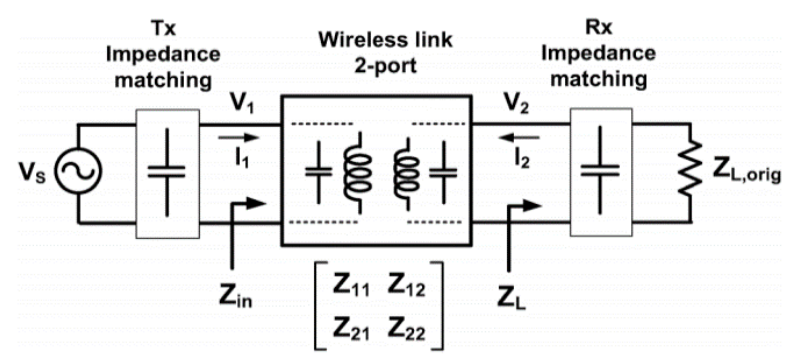

Fig. 3. Equivalent circuit to calculate Power Transfer Efficiency (PTE) between the Tx (transmitting, external) and the Rx (receiving, internal) coils (see also [4]). 


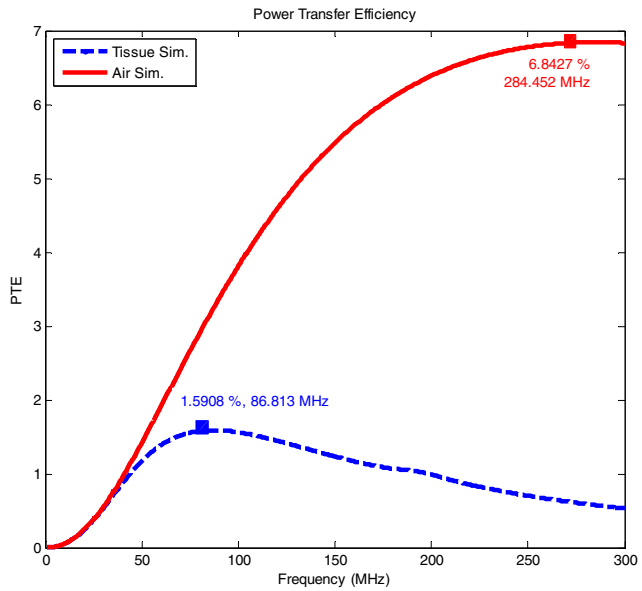

Fig. 4. Power Transfer Efficiency (PTE) from the 1-turn Tx coil of $24 \mathrm{~mm}$ in diameter to the 7-turn Rx coil of $1 \mathrm{~mm}$ in diameter at $12 \mathrm{~mm}$ distance. Two scenarios are considered: The system in either in the air or the Rx coil is placed inside a cylindrical arm model (see Fig. 2) at $10 \mathrm{~mm}$ depth beneath the skin - air interface with the Tx coil at $2 \mathrm{~mm}$ distance from the skin -air interface.

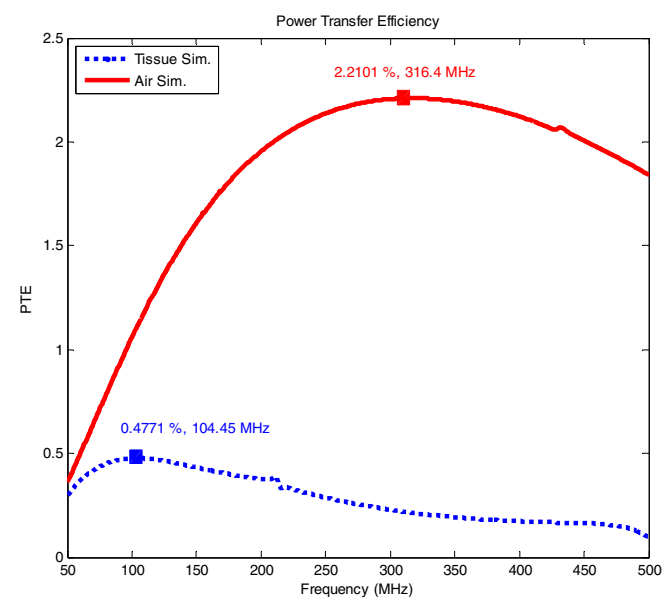

Fig. 5. Power Transfer Efficiency (PTE) from the 1-turn Tx coil of $24 \mathrm{~mm}$ in diameter to the 7-turn $\mathrm{Rx}$ coil of $1 \mathrm{~mm}$ in diameter when placed inside the antenna. The distance between the two coils is equal to $12 \mathrm{~mm}$. Two scenarios are considered: The system is either in the air or the antenna-Rx coil configuration is placed inside a cylindrical arm model (see Fig. 2) at 10 $\mathrm{mm}$ depth beneath the skin - air interface with the Tx coil at $2 \mathrm{~mm}$ distance from the skin air interface.

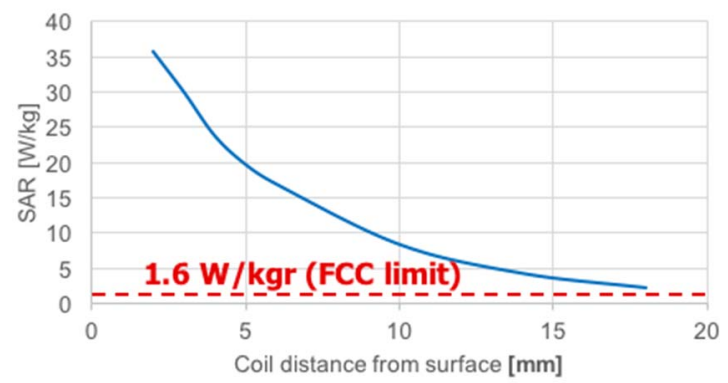

Fig. 6. Averaged SAR over $1 \mathrm{~g}$ of tissue for the Tx coil when it is moving away from the Rx coil. The stiched line denotes the SAR averaged over $1 \mathrm{~g}$ limit for publix exposure [17]. Distance is measured in $\mathrm{mm}$.

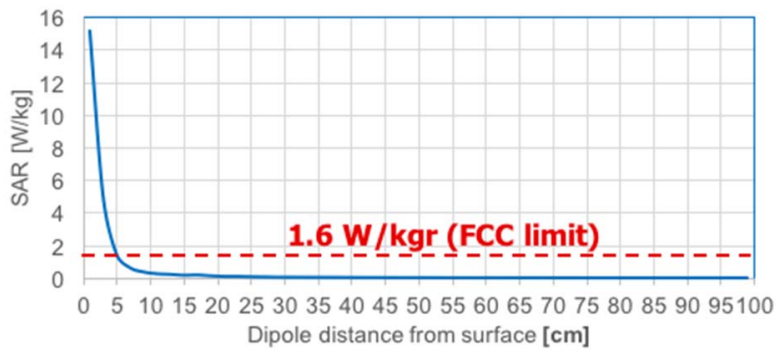

Fig. 7. Averaged SAR over $1 \mathrm{~g}$ of tissue for the Tx dipole when it is moving away from the antenna. The stiched line denotes the SAR averaged over $1 \mathrm{~g}$ limit for publix exposure [17]. Distance is measured in $\mathrm{cm}$.

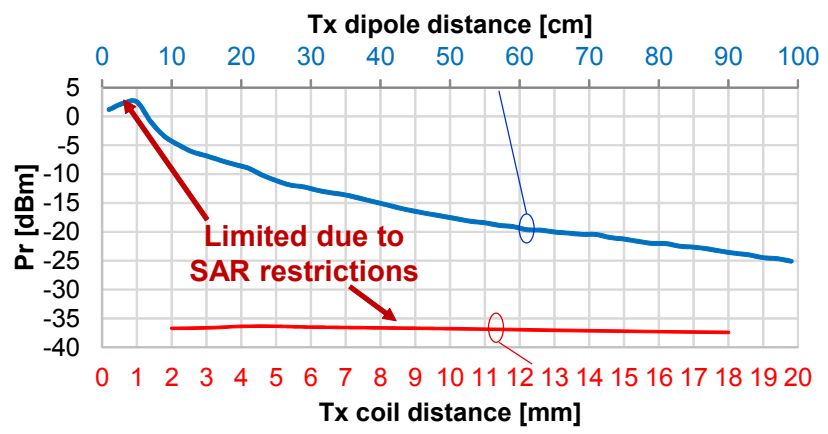

Fig. 8. Received power from the implanted antenna (denoted with blue) or the Rx coil (denoted with red). Top horizontal axis $(\mathrm{cm})$ refers to the dipole while bottom horizontal axis $(\mathrm{mm})$ reffers to the Tx coil

diameter. The radiating power charging is carried out at 915 $\mathrm{MHz}$ while the inductive charging is applied at $104.45 \mathrm{MHz}$. The objective is to estimate receiver's sensitivity to collect RF signals for wireless power transmission as a function of distance (D) between the transmitter and the surface. Key factors such as i) the implanted antenna gain, ii) the transmitting power $\left(\mathrm{P}_{\mathrm{t}}\right)$ regulated by Specific Absorption Rate (SAR) [17] and effective isotropic radiated power (EIRP) restrictions [18], and iii) the path losses considerably determine the power $\left(\mathrm{P}_{\mathrm{r}}\right)$ received by the implanted PIFA Initial results for the case of an external dipole radiating at maximum allowed power (restricted at $1 \mathrm{~W}$ maximum -see [18]) or the $24 \mathrm{~mm}$-diameter coil radiating also at maximum power are given in Fig. 8. As seen the radiating scenario seems to be superior since the reception is at worst at $-25 \mathrm{dBm}$ for $1 \mathrm{~m}$ distance. For the inductive scenario the receiving coil cannot receive more than $-36 \mathrm{dBm}$ for distances up to $18 \mathrm{~mm}$. This great difference is on one part due to the safety SAR limits (1.6 W/kg for averaged SAR over $1 \mathrm{~g}$ of tissue, [17]). In Fig. 6, averaged SAR over 1g of tissue is given for the coilcoil configuration in relation with the distance of Tx coil. Fig. 7 contains parametric analysis with distance of averaged SAR over $1 \mathrm{~g}$ of tissue for the radiating dipole. Both transmitting coil and dipole are fed with $1 \mathrm{~W}$. As seen the Tx coil operates below SAR safety limits only at distances greater than $18 \mathrm{~mm}$. For the dipole, SAR levels are below safety limits at distance greater than $5 \mathrm{~cm}$. Since PTE for the coils is considerably affected by distance variations of few $\mathrm{mm}$ (not shown here) the receiving power from the coil cannot exceed $-36 \mathrm{dBm}$ and notably is kept stable (see Fig. 8). This is explained by the fact 
that allowable power is increasing with increasing distance of the coil from the arm surface and that efficiency deteriorates with distance. Moreover, dipole efficiency is much higher than the Tx coil efficiency.

Other coil configurations will be also investigated with the focus being on increasing the Tx-Rx coil efficiency. It seems till now that radiating charging is more efficient than inductive charging. Yet, efficiency in inductive charging can considerably increase if the diameters of $\mathrm{Rx}$ and $\mathrm{Tx}$ coils increase. In that case the redesigning of the PIFA would be necessary in order to allow for a larger loop without antenna performance degradation. This could be investigated in the future

\section{CONCLUSIONS}

Implementation of inductive wireless charging for a telemetry application is investigated by adding a coil configuration into the implanted antenna without affecting its operation. Originally the implanted antenna has double resonance supporting data transmission $(400 \mathrm{MHz})$ and energy radiating charging $(915 \mathrm{MHz})$. A comparison is also performed between inductive and radiating charging and the latter seems to be more efficient at the moment. However, by redesigning the antenna and making an effort to integrate larger coils into its structure without affecting antenna performance, would certainly allow for much more efficient inductive charging. In that case inductive charging could be complimentary to radiating energy transfer. Even more it could be an alternative solution depending on the available resources. A lot remain to be examined. As seen here inductive charging for the original coil configuration does not exceed $0.5 \%$ power transfer efficiency.

\section{REFERENCES}

[1] H. Li, Y.-X. Guo, C. Liu, S. Xiao, and L. Li, "A Miniature-Implantable Antenna for MedRadio-Band Biomedical Telemetry," IEEE Antennas Wirel. Propag. Lett., vol. 14, pp. 1176-1179, 2015.

[2] S. Bakogianni and S. Koulouridis, "An Implantable Planar Dipole Antenna for Wireless MedRadio-Band Biotelemetry Devices," IEEE Antennas Wirel. Propag. Lett., vol. 15, pp. 234-237, 2016.

[3] H.-Y. Lin, M. Takahashi, K. Saito, and K. Ito, "Performance of Implantable Folded Dipole Antenna for In-Body Wireless Communication," IEEE Trans. Antennas Propag., vol. 61, no. 3, pp. 1363-1370, Mar. 2013.

[4] D. Ahn and M. Ghovanloo, "Optimal Design of Wireless Power Transmission Links for Millimeter-Sized Biomedical Implants," IEEE Trans. Biomed. Circuits Syst., pp. 1-13, 2015.

[5] A. S. Y. Poon, S. O'driscoll, and T. H. Meng, "Optimal frequency for wireless power transmission into dispersive tissue," IEEE Trans. Antennas Propag., vol. 58, no. 5, pp. 1739-1750, 2010.

[6] J. Jian and M. Stanacevic, "Adaptive transmitting coil array for optimal power transfer in deeply implanted medical devices," in Proceedings IEEE International Symposium on Circuits and Systems, 2016, vol. 2016-July, pp. 2030-2033.

[7] A. Yakovlev, J. H. Jang, and D. Pivonka, "An 11 uW Sub-pJ/bit Reconfigurable Transceiver for mm-Sized Wireless Implants," IEEE Trans. Biomed. Circuits Syst., vol. 10, no. 1, pp. 175-185, Feb. 2016.

[8] F. J. Huang, C. M. Lee, C. L. Chang, L. K. Chen, T. C. Yo, and C. H. Luo, "Rectenna application of miniaturized implantable antenna design for triple-band biotelemetry communication," IEEE Trans. Antennas Propag., vol. 59, no. 7, pp. 2646-2653, 2011.
[9] S. Hu, J. H. Cheong, Y. Gao, M. C. K. Ho, M. Je, M. Madihian, and S. Khait, "A low-cost $2.45-\mathrm{GHz}$ wireless power link for biomedical devices," in 2012 IEEE Asia-Pacific Conference on Antennas and Propagation, 2012, pp. 215-216.

[10] C. Liu, Y.-X. Guo, H. Sun, and S. Xiao, "Design and Safety Considerations of an Implantable Rectenna for Far-Field Wireless Power Transfer," IEEE Trans. Antennas Propag., vol. 62, no. 11, pp. 5798-5806, Nov. 2014.

[11] S. Bakogianni and S. Koulouridis, "Design of a novel miniature implantable rectenna for in-body medical devices power support," in 2016 10th European Conference on Antennas and Propagation (EuCAP), 2016, pp. 1-5.

[12] S. Koulouridis, S. Bakogianni, A. Diet, Y. Le Bihan, and L. Pichon, "Investigation of Efficient Wireless Charging for Deep Implanted Medical Devices," in IEEE Antennas and Propagation Society, AP-S International Symposium (Digest), 2016, pp. 1-4.

[13] R. A. Bercich, D. R. Duffy, and P. P. Irazoqui, "Far-Field RF Powering of Implantable Devices: Safety Considerations," IEEE Trans. Biomed. Eng., vol. 60, no. 8, pp. 2107-2112, Aug. 2013.

[14] C. Gabriel, S. Gabriel, E. Corthout, and et all, "The dielectric properties of biological tissues: I. Literature survey," Phys. Med. Biol., vol. 41, no. 11, pp. 2231-2249, Nov. 1996.

[15] S. Gabriel, R. W. Lau, C. Gabriel, and et al., "The dielectric properties of biological tissues: III. Parametric models for the dielectric spectrum of tissues," Phys. Med. Biol., vol. 41, no. 11, pp. 2271-2293, Nov. 1996.

[16] S. Gabriel, R. W. Lau, C. Gabriel, and et al., "The dielectric properties of biological tissues: II. Measurements in the frequency range $10 \mathrm{~Hz}$ to 20 GHz," Phys. Med. Biol., vol. 41, no. 11, pp. 2251-2269, Nov. 1996.

[17] "C95.1-2005 IEEE Standard for Safety Levels with Respect to Human Exposure to Radio Frequency Electromagnetic Fields, $3 \mathrm{kHz}$ to 300 GHz."

[18] "FCC Rules for Wireless Equipment operating in the ISM bands www.afar.net." [Online]. Available: http://www.afar.net/tutorials/fccrules. 